\title{
PENGARUH DANA ALOKASI KHUSUS, DANA BAGI HASIL DAN DANA ALOKASI UMUM TERHADAP ANGGARAN PENDAPATAN DAN BELANJA DAERAH KABUPATEN LUWU
}

\author{
Hapid $^{1}$, Muh. Halim ${ }^{2}$, Yuli Wulandari ${ }^{3}$ \\ 1) Dosen Sekolah Tinggi Ilmu Ekonomi Muhammadiyah Palopo \\ ${ }^{2,3)}$ Dosen Sekolah Tinggi Ilmu Ekonomi Muhammadiyah Palopo
}

\begin{abstract}
Abstrak: Tujuan penelitian ini yaitu untuk mengetahui Pengaruh Dana Alokasi Khusus, Dana Bagi Hasil dan Dana Alokasi Umum Terhadap Anggaran Pendapatan dan Belanja Daerah Kabupaten Luwu. Adapun teknik pengumpulan data yang penulis lakukan dalam penelitian ini, yaitu : Teknik dokumentasi, Teknik Wawancara, Teknik Kepustakaan. Dengan menggunakan metode analisis rumus Analisasi Regresi Linear Berganda digunakan untuk mengukur keeratan (kekuatan) hubungan.

Nilai koefisien determinasi ganda $\left(R^{2}\right)$ sebesar 0.952 ini berarti variabel Dana Alokasi Khusus $\left(X_{1}\right)$, Dana Bagi Hasil $\left(X_{2}\right)$, dan Dana Alokasi Umum $\left(X_{3}\right)$ mempunyai kontribusi sebesar 95,2\% terhadap Anggaran Pendapatan dan Belanja Daerah $(A P B D)(Y)$ di Kabupaten Luwu. Sisanya merupakan faktor lain yang tidak diteliti.

Berdasarkan hasil uji $F$, dimana $F_{\text {hitung }}>F_{\text {tabel }}(13,297>4,28)$. Dari hasil analisis didapatkan bahwa variabel Dana Alokasi Khusus $\left(X_{1}\right)$, Dana Bagi Hasil $\left(X_{2}\right)$, dan Dana Alokasi Umum $\left(X_{3}\right)$ mempunyai pengaruh signifikan terhadap Anggaran Pendapatan dan Belanja Daerah (Y) di Kabupaten Luwu.
\end{abstract}

Kata Kunci: Dana Alokasi Khusus, Dana Bagi Hasil, Dana Alokasi Umum, Anggaran Pendapatan, Belanja Daerah

\section{PENDAHULUAN}

Desentralisasi fiskal pada intinya memberikan keleluasaan yang lebih besar kepada pemerintah daerah dalam melakukan perencanaan, pelaksanaan, pemantauan dan evaluasi berbagai kegiatan pemerintah dan pembangunan di wilayahnya. Implikasi yang diharapkan adalah pemerintah daerah dapat melaksanakan pemerintahan dan pembangunan secara efektif dan efisien, untuk kepentingan peningkatan kesejahteraan masyarakat. Dalam kaitannya dengan aspek perekonomian, desentralisasi fiskal berujung pada peningkatan kesejahteraan ekonomi masyarakat daerah. Salah satu indikator utama dalam melihat perkembangan kesejahteraan ekonomi masyarakat adalah output. Jadi, untuk meningkatkan kesejahteraan masyarakat, salah satu langkah utama yang dapat ditempuh melalui peningkatan output daerah.
Tujuan otonomi daerah untuk meningkatkan pertumbuhan ekonomi daerahnya. Salah satu ukuran pertumbuhan ekonomi daerah adalah pendapatan domestik regional bruto (PDRB). Pendapatan domestik regional bruto (PDRB) suatu daerah dapat menunjukkan seberapa besar aktivitas perekonomian secara keseluruhan. Konsep pendapatan domestik regional bruto adalah ukuran yang paling sering dipakai sebagai indikator pertumbuhan ekonomi, namun bukan satu satunya indikator pertumbuhan ekonomi domestik. Pertumbuhan ekonomi adalah sebuah proses, bukan merupakan suatu gambaran ekonomi pada suatu periode tertentu, ada perkembangan atau perubahan dan penggunaan waktu.

Melalui PDRB atas dasar harga konstan dapat dijadikan salah satu indikator guna melihat keberhasilan pertumbuhan perekonomian di suatu wilayah otonomi daerah merupakan salah satu 
bentuk reformasi pada sistem pemerintahan yang ditandai dengan lahirnya Undang-Undang Nomor 22 tahun 1999 tentang Pemerintahan Daerah dan Undang-Undang Nomor 25 tahun 1999 tentang Perimbangan Keuangan antara Pemerintah Pusat dan Daerah. Hal ini memberikan kewenangan luas kepada pemerintah daerah untuk mengatur serta mengurus kepentingan masyarakat daerah sesuai dengan prakarsa dan aspirasi masyarakat yang sejalan dengan semangat demokrasi. Kemudian pemerintah mengeluarkan kebijakan baru mengenai otonomi daerah yakni dengan pemberlakuan Undang-Undang Nomor 33 Tahun 2004 tentang Pemerintahan Daerah dan UndangUndang Nomor 34 Tahun 2004 tentang Perimbangan Keuangan antara Pemerintahan Pusat dan Daerah.

Untuk meningkatkan output kabupaten/kota maka dibutuhkan sumber pembiayaan. Salah satu pembiayaan berasal dari transfer pemerintah yaitu dari Dana Perimbangan. Dana Perimbangan terdiri dari Bagi Hasil Pajak dan Bukan Pajak (SDA), DAU, dan DAK. Dana Perimbangan sebagai faktor produksi modal yang digunakan untuk belanja pemerintah daerah guna meningkatkan output. Adanya peningkatan output dalam jangka panjang akan meningkatkan pertumbuhan ekonomi.

Pada dasarnya realisasi penerimaan dana perimbangan yang diterima Pemerintah Kabupaten Luwu setiap tahunnya mengalami peningkatan disamping itu peningkatan realisasi dana perimbangan yang diterima Pemerintah Kabupaten Luwu berimbas ke realisasi penerimaan Pendapatan Asli Daerah (PAD) Kabupetan Luwu. Ini disebabkan karena dana perimbangan yang diterima digunakan untuk membiayai pembangunan Kabupaten Luwu sehingga akan lebih meningkatkan Pendapatan Asli Daerah (PAD) Kabupaten Luwu. Dana perimbangan sangat mempengaruhi Pendapatan Asli Daerah (PAD) Kabupaten Luwu karena semakin besar dana perimbangan yang digunakan oleh Kabupaten untuk membiayai pembangunan di Kabupaten Luwu, maka akan semakin besar pula penerimaan Pendapatan Asli Daerah (PAD) Kabupaten Luwu.

\section{BAHAN DAN METODE}

Jenis data yang dikumpulkan berupa data kuantitatif dan kualitatif, yang terdiri dari data primer dan data sekunder. Populasi dalam penelitian ini adalah 4 (empat) Variabel yaitu DAK, DAU, DBH dan APBD sedangkan yang untuk sampelnya adalah Dana Alokasi Khusus, Dana Alokasi Umum dan Dana Bagi Hasil. Adapun teknik pengumpulan data yang penulis lakukan dalam penelitian ini yaitu tekni dokumentasi, teknik wawancara, dan tekni kepustakaan.

Agar data yang terkumpul nanti dapat berguna dalam upaya memecahkan permasalahan yang diteliti, maka perlu dilakukan analisis atas data metode kuantitatif dengan rumus sebagi berikut:

$Y=a+b_{1} X_{1}+b_{2} X_{2}+b_{3} X_{3}+e$

Keterangan :

$\mathrm{Y}=$ APBD Kabupaten Luwu

$\mathrm{X}_{1}=\mathrm{DAK}$

$\mathrm{X}_{2}=\mathrm{DBH}$

$\mathrm{X}_{3}=\mathrm{DAU}$

$\mathrm{a}=$ Konstanta yang diperoleh dari garis regresi 
$\mathrm{b}=$ Koefisien yang diperoleh dari garis regresi

\section{HASIL DAN PEMBAHASAN}

\section{APBD Kabupaten Luwu}

APBD adalah rencana-rencana kerja pemerintah Kabupaten Luwu yang disusun secara matang yang nanti akan dipakai sebagai pedoman dalam setiap langka pelaksanaan tugas negara, yang dibuat dan dituangka dalam bentuk anggaran. Dengan adanya Anggaran tersebut, diharapkan dapat menggambarkan perkiraan dan pengeluaran daerah yang didasarkan pada realisasi pada tahun sebelumnya serta dapat akan mengurangi ketimpangan sumber pendanaan pemerintah Kabupaten Luwu. Adapun Anggaran Pendapatan dan Belanja Daerah Kabupaten Luwu sebagai berikut

Anggaran Pendapatan dan Belanja Daerah Kab. Luwu Tahun 2009-2-014

\begin{tabular}{|c|r|}
\hline Tahun & \multicolumn{1}{|c|}{ APBD } \\
\hline 2009 & 982.665 .413 .074 \\
\hline 2010 & 1.151 .622 .519 .876 \\
\hline 2011 & 1.395 .989 .978 .901 \\
\hline 2012 & 1.394 .110 .982 .298 \\
\hline 2013 & 1.663 .044 .665 .420 \\
\hline 2014 & 1.922 .734 .516 .136 \\
\hline Jumlah & $\mathbf{3 2 1 . 2 5 5 . 6 6 9 . 7 1 8 . 1 9 9}$ \\
\hline
\end{tabular}

Berdasarkan tabel di atas, menunjukan Anggaran Pendapatan dan Belanja Daerah Kabupaten Luwu pada tahun 2009 sebesar Rp.982.665.413.074, pada tahun 2010 Anggaran Pendapatan dan Belanja Daerah Kabupaten Luwu sebesar Rp.1.151.622.519.876, pada tahun 2011 sebesar Rp.1.395.989.978.901, pada tahun 2012 sebesar Rp.1.394.110.982.298, pada tahun 2013 sebesar Rp.1.663.044.665.420 dan pada tahun 2014 sebesar Rp.1.922.734.516.136

\section{Target dan Realisasi DAK, DAU dan DBH}

Dana perimbangan merupakan salah satu pendapatan di Kabupaten Luwu. pada dasarnya dana perimbangan di Kabupaten Luwu setiap tahunnya lebih besar dibandingkan dengan Pendapatan Asli daerah Kabupaten Luwu. adapun realisasi DAK, DAU dan DBH Kabupaten Luwu sebagai berikut :

\section{Dana Alokasi Umum, Dana Alokasi Khusus dan Dana Bagi Hasil \\ Di Kabupaten Luwu Tahun 2009 - 2014}

\begin{tabular}{|c|c|c|c|c|}
\hline Tahun & DAU & DAK & DBH & Total \\
\hline 2009 & 338.393 .478 .000 & 61.667 .400 .000 & 19.250 .000 .000 & 401.985 .878 .000 \\
\hline 2010 & 366.703 .274 .200 & 50.447 .700 .000 & 21.949 .926 .994 & 439.100 .901 .194 \\
\hline 2011 & 396.747 .997 .000 & 57.323 .200 .000 & 21.723 .053 .607 & 475.794 .250 .607 \\
\hline 2012 & 475.295 .053 .000 & 54.806 .460 .000 & 17.979 .421 .702 & 548.080 .934 .702 \\
\hline 2013 & 542.118 .008 .000 & 59.690 .400 .000 & 16.895 .668 .700 & 618.704 .076 .700 \\
\hline 2014 & 595.699 .150 .000 & 68.010 .320 .000 & 11.000 .000 .000 & 674.709 .470 .000 \\
\hline
\end{tabular}




\section{Pengaruh DAK, DAU dan DBH terhadap APBD}

Dalam mengukur pengaruh Dana Alokasi Khusus, dana Alokasi Umum, dan dana Bagi Hasil Daerah terhadap Anggaran Pendapatan dan Belanja Daerah Kabupaten Luwu dapat dihitung dengan menggunakan analisis statistik.

\section{Hasil Analisa Regresi berganda}

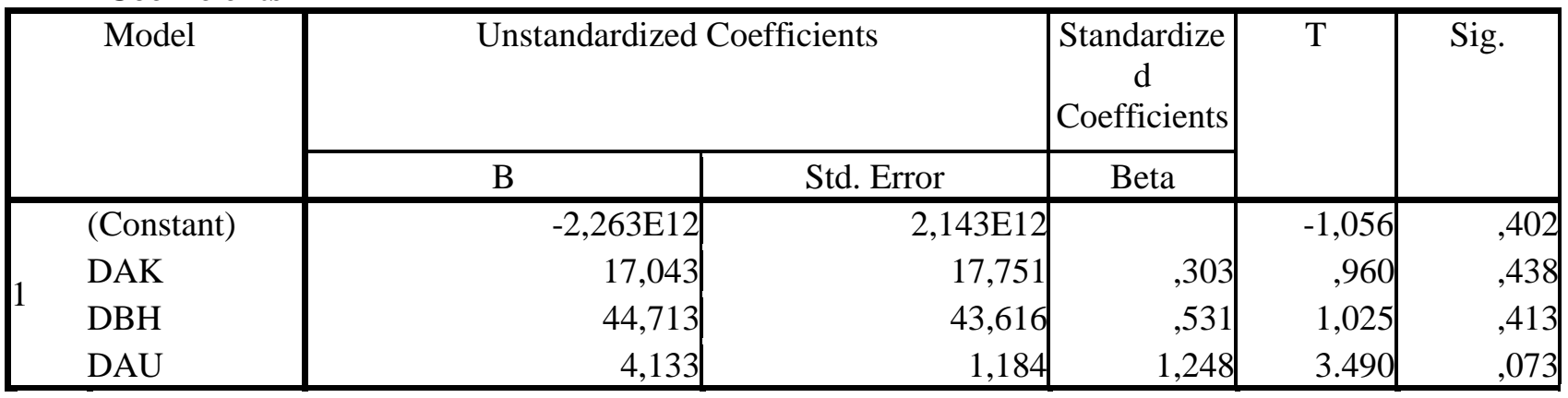

a. Dependent Variable: APBD

\section{Hasil Analisis Regresi Berganda}

Untuk mengetahui pengaruh Dana Alokasi Khusus (DAK) ,Dana Bagi Hasil (DBH), dan Dana Alokasi Umum (DAU), dan terhadap Anggaran Pendapatan dan Belanja Daerah (APBD) di Kabupaten Luwu dihitung dengan menggunakan analisis regresi berganda dengan menggunakan program SPSS 20. Adapun rekapitulasi hasil analisa korelasi dan regresi linier berganda selanjutnya dapat dilihat pada tabel sebagai berikut:
Berdasarkan hasil perhitungan yang dilakukan tentang pengaruh Dana Alokasi Khusus (DAK), Dana Bagi Hasil (DBH), dan Dana Alokasi Umum (DAU) terhadap Anggaran Pendapatan dan Belanja Daerah (APBD) di Kabupaten Luwu dengan menggunakan SPSS 20.0, maka didapatkan hasil sebagai berikut :

$Y=-2,263 E 12+17,043 x_{1}+44,713 x_{2}+4,133 x_{3}$

$\mathrm{a}=-2,263 \mathrm{E} 12$ adalah bilangan konstanta yang berarti apabila variabel bebas yaitu Dana Alokasi Khusus, Dana Bagi Hasil dan Dana Alokasi Umum sama dengan nol, maka besarnya Anggaran Pendapatan dan Belanja Daerah (APBD) di Kabupaten Luwu sebesar -2,263E12 $b_{1}=17,043$ adalah besarnya koefisien regresi variabel $\mathrm{X}_{1}(\mathrm{DAK})$ yang berarti setiap tambahan peningkatan Rp. 1000,- maka, variabel Belanja Daerah (APBD) di Kabupaten Luwu akan meningkat sebesar Rp. 17,043,-

$\mathrm{b}_{2}=44,713$ adalah besarnya koefisien regresi variabel $\mathrm{X}_{2}(\mathrm{DBH})$ yang berarti setiap peningkatan Rp. 1.000,- maka, variabel Belanja Daerah (APBD) di Kabupaten Luwu akan meningkat sebesar Rp. 44,713,-

$\mathrm{b}_{3}=4,133$ adalah besarnya koefisien regresi variabel $\mathrm{X}_{3}$ (DAU) yang berarti setiap peningkatan Rp. 1.000,- maka, variabel Belanja Daerah (APBD) di Kabupaten Luwu akan meningkat sebesar Rp. 4,133,- 
Hasil regresi pada tabel di atas menunjukan bahwa faktor $\mathrm{X}_{1}$ Dana Alokasi Khusus (DAK), $\mathrm{X}_{2}$ Dana Bagi Hasil (DBH), dan $\mathrm{X}_{3}$ dana Alokasi Umum (DAU) berpengaruh terhadap Y (APBD). Dimana setiap kenaikan yang terjadi pada variabel $\mathrm{X}$ akan di ikuti pula oleh kenaikan Y.

\section{Analisis Korelasi}

\section{Model Summary ${ }^{\mathrm{b}}$}

\begin{tabular}{|l|c|r|r|r|}
\hline Model & $\mathrm{R}$ & $\begin{array}{c}\mathrm{R} \\
\text { Square }\end{array}$ & $\begin{array}{c}\text { Adjusted R } \\
\text { Square }\end{array}$ & $\begin{array}{c}\text { Std. Error of } \\
\text { the Estimate }\end{array}$ \\
\hline 1 &, $976^{2}$ &, 952 &, 881 & $1,173 \mathrm{E} 11$ \\
\hline
\end{tabular}

a. Predictors: (Constant), DAK, DBH, DAU

b. Dependent Variable: APBD

Hasil dari analisis pengaruh Dana Alokasi Khusus (DAK), Dana Bagi Hasil (DBH), dan Dana Alokasi Umum (DAU) terhadap Anggaran Pendapatan dan Belanja Daerah (APBD) di Kabupaten Luwu pada tabel di atas, menunjukkan nilai $\mathrm{R}=0,976$ artinya hubungan positif dan kuat antara Dana Alokasi Khusus (DAK), Dana Bagi Hasil (DBH), dan Dana Alokasi Umum (DAU) serta Anggaran Pendapatan dan Belanja Daerah (APBD) di Kabupaten Luwu. Variabel Dana Alokasi Khusus (DAK), Dana Bagi Hasil (DBH), dan Dana Alokasi Umum (DAU) secara bersamasama berpengaruh terhadap Anggaran Pendapatan dan Belanja Daerah (APBD) di Kabupaten Luwu karena nilai $R$ yaitu 0,976 mendekati 1 .

Koefisien Determinasi.

Dari tabel di atas menunjukkan nilai koefisien determinasi ganda $\left(\mathrm{R}^{2}\right)$ sebesar 0,952 ini berarti variabel Dana Alokasi Khusus (DAK), Dana Bagi Hasil (DBH), dan Dana Alokasi Umum (DAU) mempunyai kontribusi sebesar 95,2\% terhadap Anggaran Pendapatan dan Belanja Daerah (Y) di
Kabupaten Luwu. Sisanya sebesar 3\% dipengaruhi oleh faktor - faktor lain yang tidak di teliti oleh peneliti. Dana Alokasi Khusus (DAK), Dana Bagi Hasil (DBH), dan Dana Alokasi Umum (DAU) berpengaruh sebesar 95,2\% terhadap Anggaran Pendapatan dan Belanja Daerah (APBD) di Kabupaten Luwu.

\section{Analisis Uji t}

Pengujian ini untuk melihat sejauh mana pengaruh secara sendiri-sendiri variabel $\mathrm{X}$ terhadap variabel $\mathrm{Y}$ berdasarkan hasil regresi yang ada pada tabel di atas. Uji t dilakukan dengan membandingkan nilai $t_{\text {hitung }}$ dengan nilai $t_{\text {tabel }}$ dengan tingkat kesalahan sebesar $5 \%$ yakni 2,447. Apabila $t_{\text {hitung }}>t_{\text {tabel }}$ maka dapat disimpulkan bahwa variabel tersebut mempunyai pengaruh yang signifikan.

Nilai $t_{\text {hitung }}$ untuk variabel Dana Alokasi Khusus (DAK) sebesar 0,960 Sementara itu nilai pada tabel distribusi 5\% sebesar 2,447. Maka $t_{\text {hitung }}$ $(0,960)<t_{\text {tabel }}(2,447)$. Hal ini berarti Dana Alokasi Khusus (DAK) $\left(\mathrm{X}_{1}\right)$ tidak berpengaruh. Nilai $t_{\text {hitung }}$ untuk variabel Dana Bagi Hasil (DBH) sebesar 1,025 Sementara itu nilai pada tabel distribusi $5 \%$ sebesar 2,447.

\section{Analisis Uji F}

Uji simultan atau uji F merupakan uji secara bersama-sama untuk menguji signifikansi pengaruh variabel Dana Alokasi Khusus (DAK) $\left(\mathrm{X}_{1}\right)$, Dana Bagi Hasil $(\mathrm{DBH})\left(\mathrm{X}_{2}\right)$, dan Dana Alokasi Umum (DAU) $\left(\mathrm{X}_{3}\right)$ serta secara bersamasama terhadap variabel Anggaran Pendapatan Dan Belanja Daerah (APBD) (Y) di Kabupaten Luwu. Uji $F$ dilakukan dengan membandingkan $F_{\text {hitung }}$ dengan $\mathrm{F}_{\text {tabel. }}$ 
ANOVA $^{\mathrm{a}}$

\begin{tabular}{|rl|r|r|r|r|r|}
\hline Model & & Sum of Squares & Df & Mean Square & F & \multicolumn{1}{c|}{ Sig. } \\
\hline \multirow{2}{*}{1} & Regression & $5,488 \mathrm{E} 223$ & 3 & $1,829 \mathrm{E} 23$ & 13,297 &, $071^{\mathrm{b}}$ \\
& Residual & $2,752 \mathrm{E} 22$ & 2 & $1,376 \mathrm{E} 22$ & & \\
& Total & $5,783 \mathrm{E} 23$ & 5 & & & \\
\hline
\end{tabular}

a. Dependent Variable: APBD

b. Predictors: (Constant), DAK, DBH, DAU

Berdasarkan hasil regresi dari tabel di atas menunjukkan $F_{\text {hitung }}$ sebesar 13,297, sedangkan $\mathrm{F}_{\text {tabel }}$ pada tabel distribusi pada tingkat kesalahan $5 \%$ adalah sebesar 5,05. Hal ini berarti $\mathrm{F}_{\text {hitung }}>\mathrm{F}_{\text {tabel }}$ $(13,297>4,28)$. Perhitungan tersebut menunjukkan bahwa Dana Alokasi Khusus $\left(\mathrm{X}_{1}\right)$, Dana Bagi Hasil $\left(\mathrm{X}_{2}\right)$, dan Dana Alokasi Umum $\left(X_{3}\right)$ secara bersama-sama mempunyai pengaruh signifikan terhadap variabel Anggaran Pendapatan Dan Belanja Daerah (Y) di Kabupaten Luwu.

\section{SIMPULAN}

1) $-2,263 \mathrm{E} 12$ adalah bilangan variabel bebas yaitu Dana Alokasi Khusus, Dana Bagi Hasil dan Dana Alokasi Umum sama dengan nol, maka besarnya Anggaran Pendapatan dan Belanja Daerah (APBD) di Kabupaten Luwu sebesar 2,263E12. Untuk 17,043 adalah besarnya koefisien regresi variabel $\mathrm{X}_{1}(\mathrm{DAK})$ yang berarti setiap tambahan peningkatan Rp. 1000,- maka, variabel Belanja Daerah (APBD) di Kabupaten Luwu akan meningkat sebesar Rp. 17,043. Dan untuk 44,713 adalah besarnya koefisien regresi variabel $\mathrm{X}_{2}$ (DBH) yang berarti setiap peningkatan Rp. 1.000,maka, variabel Belanja Daerah (APBD) di Kabupaten Luwu akan meningkat sebesar Rp. 44,713 . Sedangkan untuk 4,133 adalah besarnya setiap peningkatan Rp. 1.000,- maka, variabel Belanja Daerah (APBD) di Kabupaten Luwu akan meningkat sebesar

Rp. 4,133,-

2) Nilai koefisien determinasi ganda $\left(R^{2}\right)$ sebesar 0.952 ini berarti variabel Dana Alokasi Khusus $\left(\mathrm{X}_{1}\right)$, Dana Bagi Hasil $\left(\mathrm{X}_{2}\right)$, dan Dana Alokasi Umum $\left(\mathrm{X}_{3}\right)$ mempunyai kontribusi sebesar 95,2\% terhadap Anggaran Pendapatan dan Belanja Daerah (APBD) (Y) di Kabupaten Luwu. Sisanya merupakan faktor lain yang tidak diteliti.

3) Berdasarkan hasil uji F, dimana $F_{\text {hitung }}>$ $F_{\text {tabel }}(13,297>4,28)$. Dari hasil analisis didapatkan bahwa variabel Dana Alokasi Khusus $\left(\mathrm{X}_{1}\right)$, Dana Bagi Hasil $\left(\mathrm{X}_{2}\right)$, dan Dana Alokasi Umum $\left(\mathrm{X}_{3}\right)$ mempunyai pengaruh signifikan terhadap Anggaran Pendapatan dan Belanja Daerah (Y) di Kabupaten Luwu.

4) Variabel yang paling dominan berpengaruh signifikan terhadap Anggaran Pendapatan dan Belanja Daerah (APBD) di Kabupaten Luwu adalah variabel Dana Alokasi Umum (DAU) karena memiliki nilai $\mathrm{T}_{\text {hitung }}$ yang paling besar yaitu 3.490

\section{DAFTAR PUSTAKA}

Undang-undang Nomor 33 Tahun 2004 tentang Perimbangan Keuangan Daerah 


$\begin{array}{lr}\text { Republik Peraturan Menteri } & \begin{array}{r}\text { Keuangan } \\ \text { Nomor }\end{array} \\ \text { 165/PMK.07/2012 tentang Pengalokasian } \\ \text { Anggaran Transfer ke Daerah }\end{array}$

Abimanyu, Anggito. 2005. Format Anggaran Terpadu Menghilangkan Tumpang Tindih. Bapekki Depkeu.

Bawono, Bernanda Gatot Tri. 2008. Pengaruh Dana Alokasi Umum (DAU) dan Pendapatan Asli Daerah (PAD) terhadap Belanja Pemerintah Daerah: Studi Kasus Kabupaten/Kota di Jawa Barat dan Banten). Tesis. UII. Yogyakarta.

Bungin, HM. Burhan, 2005. Metode Penelitian Kuantitatif : Komunikasi, Ekonomi, dan Kebijakan Publik serta Ilmu-Ilmu Sosial Lainnya, Edisi Pertama, Cetakan kedua, Jakarta : Prenada Media Group.

Igbal M hasan, 1999, Pokok-pokok Materi Statistik I \& II, Cetakan Pertama, Penerbit Bumi Aksara, Jakarta.

Kartasasmita, 2007. Dasar-dasar Perpajakan, Cetakan Kedua, Penerbit CV Rajawali Press, Jakarta.

Machfud, 2003, Titik Berat Otonomi Daerah Pada Derah Tingka II, Penerbit Rhineka Cipta, Jakarta.

Mardiasmo, 2002, Ekonomi Pembangunan, Cetakan Kedua. Trinologi Bandung

Mochammad Rizky.2011, Efektifitas Penerimaan Dana Perimbangan di Kabupaten Cilacap.

Prakosa, Kesit Bambang. 2004. Pengaruh Dana Alokasi Umum (DAU) dan Pendapatan Asli Daerah (PAD) terhadap Prediksi Belanja Daerah (Studi Empirik di wilayah Provinsi Jawa Tengah dan DIY). JAAI Vol. 8 No. 2.

Revrisond Baswir, 2000, Akuntansi Pemerintahan Indonesia, Yogyakarta: Balai Penerbit Fakultas Ekonomi.
Samudra, 2005. Akuntansi Pajak, Penerbit Salemba Empa, Jakarta.

Sugiyono, 2001. Metode Penelitian Bisnis, Cetakan ketiga, Bandung : Alfabeta Bandung.

Suharyadi, 2003. Statistika Untuk Ekonomi dan Keuangan Modern, Buku 1, Jakarta : Salemba Empat.

Suparmoko, M. 2001. Keuangan Negara dalam Teori dan Praktek. Yogyakarta: BPFE.

Usman, Marzuki, 2003, Keuangan dan Pembiayaan Pembangunan Daerah, Penerbit Liberty, Yogyakarta.

Widjaya, Amin, Tunggal, 2004, Titik Berat Otonomi Daerah Pada Derah Tingka II, Penerbit Rhineka Cipta, Jakarta. 